Research Article

\title{
Synthesis of Polytetrahydrofuran Using Protonated Kaolin as A Solid Acid Catalyst
}

\author{
Abdelhak Moumen ${ }^{1,2^{*}}$, Zhour Hattab ${ }^{1}$, Youghourta Belhocine ${ }^{2}$, Kamel Guerfi ${ }^{1}$, \\ Nacer Rebbani ${ }^{1}$
}

${ }^{1}$ Laboratory of Water Treatment and Valorization of Industrial Waste, Department of Chemistry, Faculty of Sciences, Badji-Mokhtar University, BP12, 23000, Annaba, Algeria

${ }^{2}$ Department of Petrochemical and Process Engineering, Faculty of Technology,

University of 20 Août 1955 Skikda, Algeria

Received: 2nd May 2018; Revised: 28th November 2018; Accepted: $12^{\text {nd }}$ December 2018; Available online: 30th April 2019; Published regularly: 1st August 2019

\begin{abstract}
In this work, a non-toxic protonated kaolin clay exchanged with protons, was successfully applied as a solid acid catalyst for the polymerization of tetrahydrofuran (poly(THF)) at room temperature in the presence of acetic anhydride. Prior to using the kaolin as a catalyst, it was treated with $\mathrm{HCl}(0.1 \mathrm{M})$ and characterized using various analytical techniques. The amounts of catalyst and reaction time on the conversion of THF were investigated. Characterizations of nuclear magnetic Resonance of proton (1H-NMR), Fourier Transform Infrared spectroscopy (FT-IR), X-ray Diffraction (XRD), Optical Microscopy $(\mathrm{OM})$, and Differential Scanning Calorimetry (DSC) techniques were used to examine the resulting polymer. X-ray characterization and DSC data indicated that the obtained poly(THF) is a highly crystalline substance. The results showed that protonated kaolin $\left(\right.$ kaolin- $\left.\mathrm{H}^{+}\right)$has a high catalytic activity for the polymerization of THF with a conversion rate of $50.02 \%$ after 20 hours. Copyright (C) 2019 BCREC Group. All rights reserved
\end{abstract}

Keywords: polymer synthesis; cationic polymerization; protonated kaolin clay; polytetrahydrofuran

How to Cite: Moumen, A., Hattab, Z., Belhocine, Y., Guerfi, K., Rebbani, N. (2019). Synthesis of Polytetrahydrofuran Using Protonated Kaolin as A Solid Acid Catalyst. Bulletin of Chemical Reaction Engineering \& Catalysis, 14 (2): 294-300 (doi:10.9767/bcrec.14.2.2605.294-300)

Permalink/DOI: https://doi.org/10.9767/bcrec.14.2.2605.294-300

\section{Introduction}

Many researchers have been interested in the polymerization of THF because of its industrial applications in the synthesis of plastic and fiber materials [1-8]. The polymerization can be initiated by electrophilic agents, such as: Brønsted acids $\left(\mathrm{HCl}, \mathrm{H}_{2} \mathrm{SO}_{4}, \mathrm{HClO}_{4}\right.$, etc.) and Lewis acids $\left(\mathrm{AlCl}_{3}, \mathrm{BF}_{3}, \mathrm{OEt}_{2}, \mathrm{TiCl}_{4}\right.$, etc.) [9]. However, the Brønsted acids were very harmful

*Corresponding Author.

E-mail: abdo_moumen@yahoo.fr (A. Moumen),

Telp: +213791892995 protonic acids, corrosives, and expensive, while the Lewis acids required the use of a large amount. To overcome these drawbacks and to avoid the environmental pollution, the application of clean, economical, and efficient processes for the polymerization of THF requires immediate attentions. For this purpose, the use of nontoxic heterogeneous catalysts instead the mentioned homogenous catalysts can be an efficient solution method [10]. Regarding the application of heterogeneous catalysis for the polymerization process, over the last few decades, several research groups have valorized and applied some natural materials based on clays that have 
been already used as solid catalysts for the polymerization of vinyl, heterocyclic and ester monomers [11-23]. Among these clay materials, the kaolin, a class of inexpensive and a new non-toxic cationic catalyst, exhibited much higher catalytic reactivities in different organic synthesis processes [10,24-25]. Many works have been devoted to the polymerization of heterocyclic monomers, such as: THF using clays as catalysts [22,26]. Recently, Ouis et al. [22] have studied the polymerization of THF using the kaolin of Tamazert (Mila, Algeria). The results of their research confirmed the high efficiency of kaolin for the THF polymerization where the conversion rate was $56 \%$ by the use of $15 \%$ of kaolin.

In the present study, a local kaolin obtained from the region of Guelma (north-eastern Algeria) is used as a solid catalyst in an attempt to enhance the process of THF polymerization. In order to reduce the reaction time and the amount of kaolin applied and to increase the conversion rate of THF by improving the catalyst acidity [27], the kaolin has been treated by $\mathrm{HCl}$ before its use. The kaolin used is whitish hydrothermal kaolin, much less plastic than most sedimentary clays and very refractor.

Two parameters were considered in the present study on the monomer conversion rate, the effect of the amount of catalyst and the reaction time. One of the most important advantages of the use of solid catalysts is certainly the easy separation of Kaolin- $\mathrm{H}^{+}$particles from the polymer after the reaction and therefore, can be regenerated and reused [28]. The kaolin used in this work has been characterized using different analytical methods such as X-Ray Fluorescence (XRF), FT-IR, Scanning Electron Microscopy (SEM), Thermogravimetric Analysis (TGA), Brunauer- Emmett-Teller (BET) surface area, and X-ray Diffraction (XRD) [29]. The obtained poly(THF) was identified and characterized using ${ }^{1} \mathrm{H}-\mathrm{NMR}$, FTIR, XRD, OM, and DSC.

\section{Materials and Methods}

\subsection{Materials and Reagents}

The materials and reagents needed in this study were obtained from the following sources: tetrahydrofuran (THF, 99\%, BIOCHIM) was distilled over $\mathrm{CaH}_{2}$ under argon atmosphere before use; acetic anhydride (98\% BIOCHIM); hydrochloric acid (37\% w/w Fluka) and methanol (99\%); local kaolin clay was procured from ECVE (society of ceramic) Guelma (Eastern Algeria).

\subsection{Preparation of the Catalyst (Kaolin- $\mathrm{H}^{+}$)}

Kaolin- $\mathrm{H}^{+}$was prepared according to the procedure described in the literature [11], it has been washed respectively with distilled water and by $\mathrm{H}_{2} \mathrm{O}_{2}$ at $70{ }^{\circ} \mathrm{C}$. Acid treatment by $\mathrm{HCl}(0.1 \mathrm{M})$ until saturation was achieved over 2 days at room temperature. Kaolin $-\mathrm{H}^{+}$was then isolated by filtration and dried at $105{ }^{\circ} \mathrm{C}$. This process was repeated until the disappearance of chloride ion by checking the filtrate by adding one drop of $0.1 \mathrm{M} \mathrm{AgNO}_{3}$.

\subsection{Catalyst and Polymer Characterization}

The details of the characterization techniques of catalyst (kaolin) by different methods (X-Ray Fluorescence (XRF), Fourier Transform Infra red spectroscopy (FT-IR), Scanning Electron Microscopy (SEM), Thermogravimetric Analysis (TGA), Brunauer-Emmett-Teller (BET) surface area, and X- ray Diffraction (XRD)) were reported in our previous paper [29]. In the present paper, the chemical composition of the catalyst was determined with XRay Fluorescence (XRF) method using a Siemens type apparatus (SRS3000).

The chemical structure of the polymer was characterized according to the following procedure: ${ }^{1} \mathrm{H}-\mathrm{NMR}$ spectra were obtained in $\mathrm{CDCl}_{3}$ with a Bruker AC 250 spectrometer using tetramethylsilane (TMS) as an internal standard. The IR absorption spectrum was recorded by an FTIR-spectrometer THERMO SCIENTIFIC NICOLET IS 10 . The value of $T_{m}$ was measured by a DSC 822 instrument from Mehler Toledo with a heating rate of $5{ }^{\circ} \mathrm{C} / \mathrm{min}$ under nitrogen atmosphere. The X-ray diffraction spectrum was obtained using an X'pertPROPANalytical diffractometer. Surface analysis was examined using optical microscope of Richter type with magnifications up to G1200 equipped with a video camera type LEICA and computer-controlled.

\subsection{Synthesis of Poly(THF)}

Synthesis of the poly(THF) was carried out in a two-necked flask. The procedure was realized by mixing of $10 \mathrm{~g}(0.138 \mathrm{~mol})$ of THF with the kaolin at different weight ratios (g/g) ranging from 1 to $10 \%(1,3,5,8$, and $10 \%)$ and 0.3 $\mathrm{g}$ of acetic anhydride (3\% of the weight of monomer). Preliminary tests were achieved to optimize the amount of acetic anhydride in the reactional mixture. The optimal ratio of acetic anhydride was $3 \%$ of the weight of monomer. The reactions were carried out with magnetic stirring under argon at room temperature for 
different reaction times $(3,5,10,15,20$, and 24 h). The nomenclature of polymer samples obtained from this experiment is of the following form poly(THF)_(mass fraction of kaolin)_(reaction time in h). The kaolin was recovered by simple filtration. The polymer was precipitated into an excess of cold methanol and dried under vacuum.

\section{Results and Discussion}

\subsection{Characterization of the Catalyst}

The results of the elemental analysis of used Kaolin are presented in Table 1. The kaolin consists mainly of $\mathrm{SiO}_{2}, \mathrm{Al}_{2} \mathrm{O}_{3}$, and water which confirms the typical composition of hydrated aluminum silicates materials. The surface area of the kaolin treated with $\mathrm{HCl}$ is $56.45 \mathrm{~m}^{2} / \mathrm{g}$. The results of the characterization of the kaolin by different methods (XRF, FTIR, SEM, TGA, $\mathrm{BET}$, and XRD) were reported in our previous paper [29].

\subsection{Polymerization Reaction}

THF is well known to be polymerized by protonic acid, in the presence of acetic anhydride. The cationic polymerization of THF was initiated in this work using kaolin- $\mathrm{H}^{+}$as a solid catalyst at room temperature; the reaction of the polymerization of THF can be summarized in Scheme 1.

The IR measurements of the product are in good agreement with the structure and composition of poly(THF) (Figure 1). Vibrations observed at $1740 \mathrm{~cm}^{-1}, 2862 \mathrm{~cm}^{-1}$, and $1104 \mathrm{~cm}^{-1}$ are respectively characteristic of $\mathrm{C}=\mathrm{O}, \mathrm{CH}$, and CO groups. The vibrations at 995,563 , and 745 $\mathrm{cm}^{-1}$ were attributed to the crystalline structure of poly(THF) [30]. The results deduced from the ${ }^{1} \mathrm{H}-\mathrm{NMR}$ spectrum (Figure 2) confirm the structure of the poly(THF) resulting from the

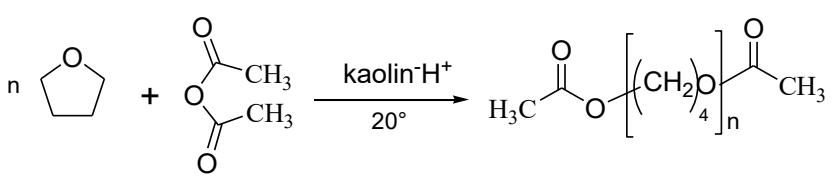

Scheme 1. Polymerization of THF using kaolin- $\mathrm{H}^{+}$ polymerization and they adapted the results described by Ouis et al. [22].

Indeed the signals at 1.65 and $3.4 \mathrm{ppm}$ correspond to the two groups $\left(\mathrm{CH}_{2}-\mathrm{CH}_{2}-\mathrm{CH}_{2}-\mathrm{CH}_{2}\right.$ $\mathrm{O}$ ), whereas those at 4.1 and $4.0 \mathrm{ppm}$ correspond to the two groups $\left(\mathrm{O}=-\mathrm{CO}-\left[\mathrm{CH}_{2} \mathrm{CH}_{2}\right.\right.$ $\left.\mathrm{CH}_{2}-\mathrm{CH}_{2}\right]$ ), and finally those at 1.92 and $2 \mathrm{ppm}$ are assigned to the two methyl groups. The thermogram of the poly(THF) (Figure 3) presents a DSC endothermic peak at $39.67{ }^{\circ} \mathrm{C}$ which corresponds to the melting temperature of the product. The presence of a fine single peak during melting process indicates that poly(THF) homopolymer is highly crystalline. The crystallinity rate of the sample $X_{c}$ is calculated from the relation: $X_{c}=\Delta H_{m} / \Delta H_{m o}$. Where $H_{m}$ is the value of the enthalpy of melting of

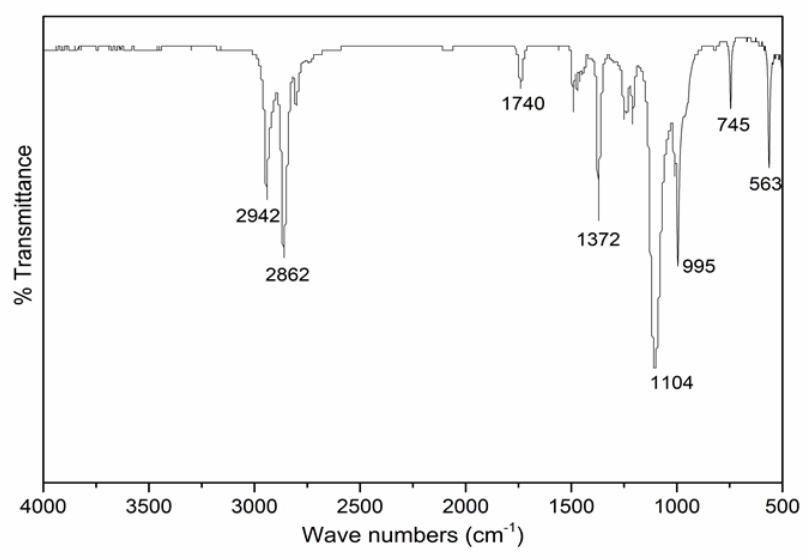

Figure 1. The FTIR spectrum of poly(THF) _0.5_5

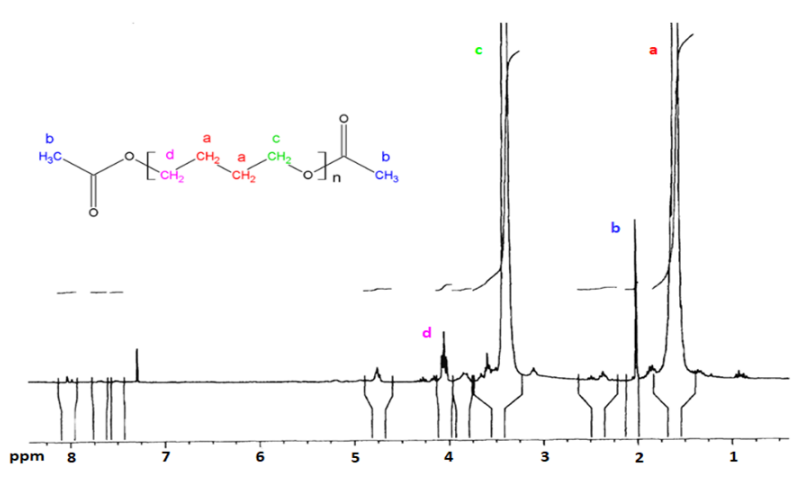

Figure 2. $\mathrm{H}^{1}$ NMR spectrum of poly(THF) _0.5_20

Table 1. Elemental composition of the Kaolin of Guelma

\begin{tabular}{cccccccc}
\hline Oxides & $\mathrm{SiO}_{2}$ & $\mathrm{Fe}_{2} \mathrm{O}_{3}$ & $\mathrm{Al}_{2} \mathrm{O}_{3}$ & $\mathrm{CaO}$ & $\mathrm{MgO}$ & $\mathrm{MnO}$ & $\mathrm{H}_{2} \mathrm{O}$ \\
\hline Weight (\%) & 43.82 & 0.20 & 36.90 & 0.23 & 0.03 & 0.025 & 18.51 \\
\hline
\end{tabular}


the sample and $H_{m o}$ the enthalpy of fusion of the polymer $100 \%$ crystalline. The literature melting enthalpy of a $100 \%$ crystalline poly(THF) sample is $175 \mathrm{~J} / \mathrm{g}$; the melting enthalpy of poly(THF) is $33.943 \mathrm{~J} / \mathrm{g}$, therefore its degree of crystallinity is $19.39 \%$.

The X-ray diffraction provides information about the morphological state of poly(THF) polymer and its degree of crystallinity. The narrow peaks of the spectrum shown in Figure 4 confirm the good crystallinity of the poly(THF). Using the optical microscopy, a bright spherical regions indicating a semi-crystalline spherulitic morphology of poly(THF) were observed (Figure $5)$. The crystalline lamellae are separated from each other by the amorphous phase which appears black.

\subsection{Catalyst Reactivity}

The reactivity of the catalyst used in the polymerization of tetrahydrofuran was examined by studying the effect of kaolin $-\mathrm{H}^{+}$amount

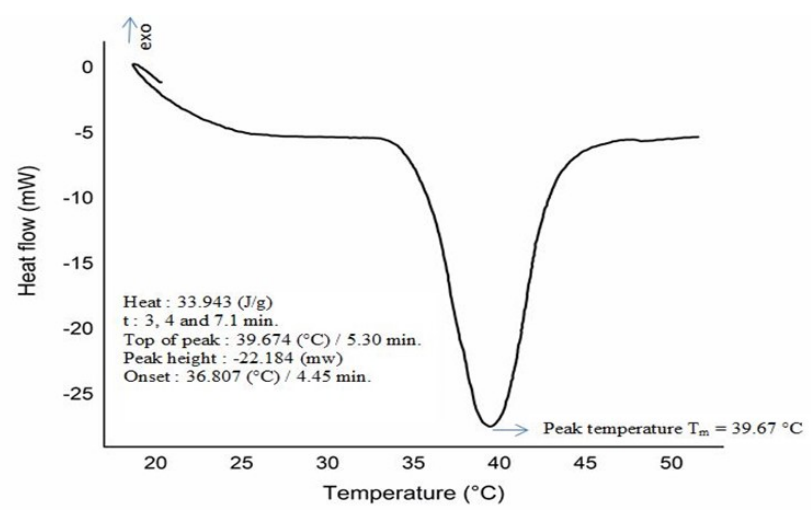

Figure 3. DSC Thermogram of poly(THF) _0.5_20 with a heating rate of $5{ }^{\circ} \mathrm{C} / \mathrm{min}$

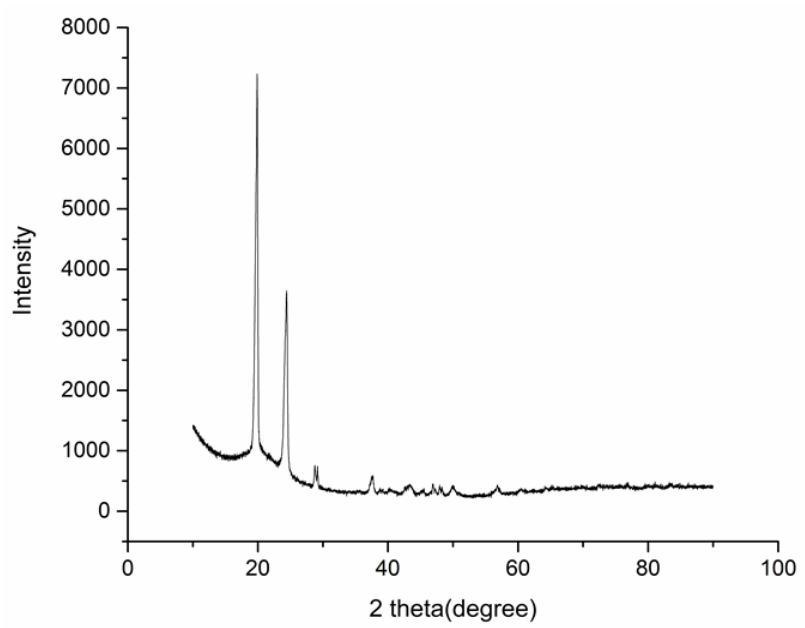

Figure 4. X-ray diffraction pattern of Poly(THF)_ 0.5_5 and time on the conversion of tetrahydrofuran.

3.3.1 Effect of the amount of Kaolin- $\mathrm{H}^{+}$on the conversion of the THF

Figure 6 shows that the variation of the weight ratio of kaolin from 1 to $10 \%$ (\% of AA set at $3 \%$ ) leads to an increase of the conversion rate of the monomer to the polymer. This study was carried out while keeping the amounts of the other reagents constant. When the amount of the catalyst increases, the number of active sites available for reaction is larger and therefore allows obtaining a rate of $50.02 \%$ with $8 \%$ of kaolin. However, an increase of the fraction of kaolin beyond $8 \%$ causes a sharp drop in the conversion rate from $50.02 \%$ to $10.1 \%$. Similar results were found by Yahiaoui et al. [10] for the polymerization of cyclohexene oxide by Mag- $\mathrm{H}^{+}$and by Belmokhtar et al. [19] for the polycondensation of pyrrole and benzaldehyde catalysed by Maghnite$\mathrm{H}^{+}$, and by Reguieg et al. [31] in one-step synthesis of Bis-macromonomers of poly(1,3dioxolane) catalyzed by Maghnite- $\mathrm{H}^{+}$. The decrease in activity is mainly due to the difficul-

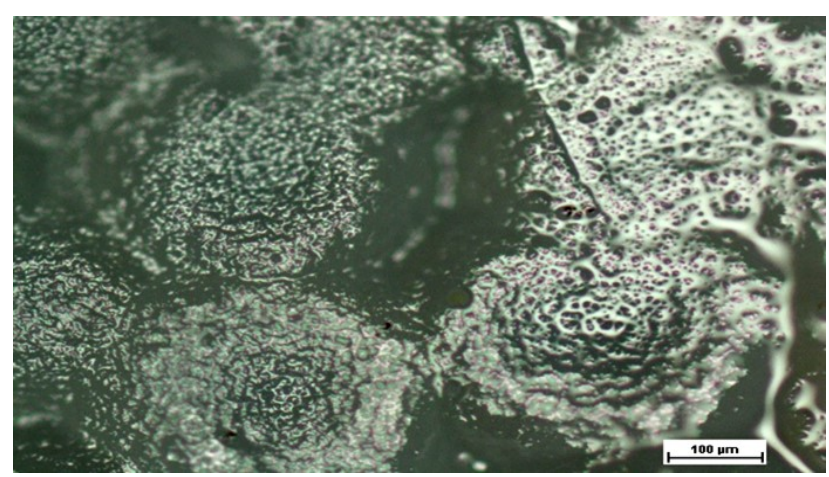

Figure 5. Optical microscopy images of poly(THF)

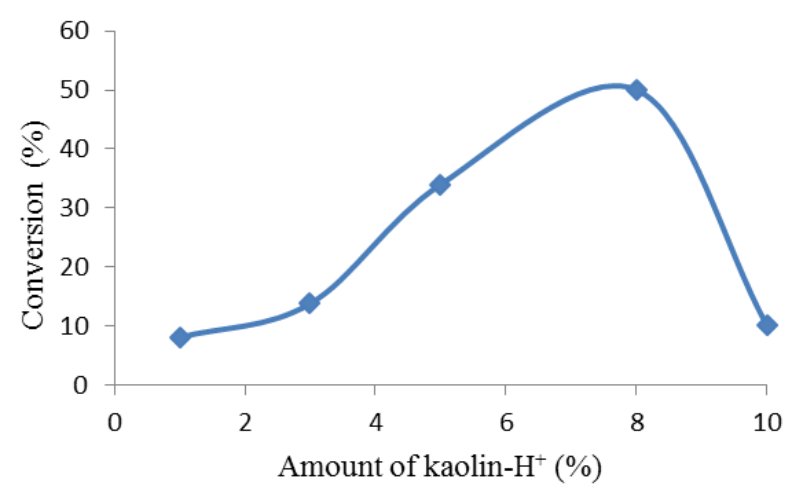

Figure 6. Evolution of the conversion of the THF as a function of the fraction of the kaolin$\mathrm{H}^{+}$ 
ties encountered by the reactants to approach and reach the active sites due to congestion. A large amount of catalyst (kaolin- $\left.\mathrm{H}^{+}\right)$creates particle agglomerations, which reduces the total adsorption area and therefore a decrease in the catalytic activity.

\subsubsection{Effect of reaction time on the conversion of the $\mathrm{THF}$}

The study of the influence of reaction time on the conversion rate of the THF, Figure 7 showed that the maximum yield of $50.02 \%$ is obtained after 20 hours of reaction. The initiation of the polymerization of THF is not done directly by kaolin, the presence of acetic anhydride acts as a transfer agent which makes this polymerization feasible, this process is carried out in two sub-steps:

The first step begins with the protonic addition of treated kaolin to the acetic anhydride

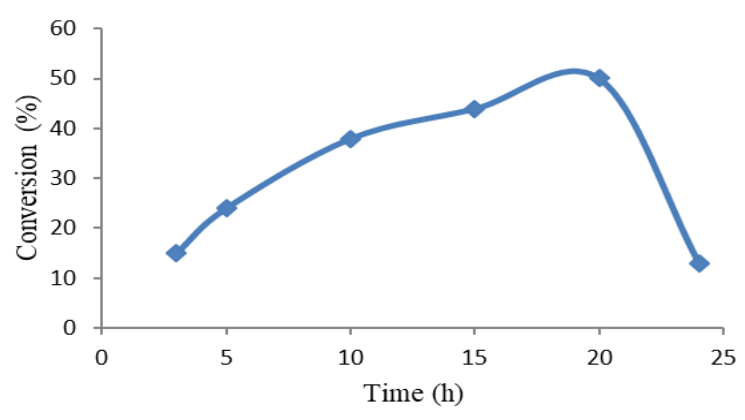

Figure 7. Evolution of the conversion of the $\mathrm{THF}$ as a function of reaction time with a fraction of $8 \%$ kaolin
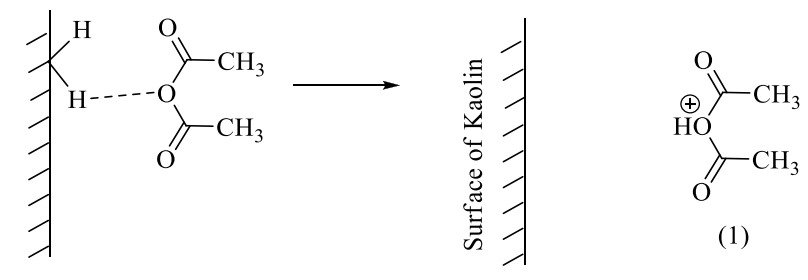

Kaolin- $\mathrm{H}^{+}$

Scheme 2. Protonation of acetic anhydride
(Scheme 2) according to the following reaction. The second step is the nucleophilic attack of the protonated acetic anhydride by a monomer molecule involving the formation of a molecule of acetic acid (Scheme 3). The propagation step would be the opening of the ring of the molecule (a) to achieve a straight chain stable energetically. The stopping of the growth of the chain is the result of the presence of the acetic acid of the initiation stage (Scheme 4).

\section{Conclusion}

In summary, a successful synthesis of poly(THF) has been reported. The kaolin- $\mathrm{H}^{+}$ used in this study has proved to be an effective catalyst for the ring opening polymerization reaction of THF. The various techniques used, such as: FT-IR, ${ }^{1} \mathrm{H}-\mathrm{NMR}$, DSC, optical microscopy and XRD, show that kaolin- $\mathrm{H}^{+}$initiates the polymerization process of THF by achieving $50.02 \%$ conversion rate and yields a crystalline polymer with a temperature of melting $T_{m}$ of $39.67{ }^{\circ} \mathrm{C}$. The optimum reaction conditions for the polymerization of THF are $8 \mathrm{wt} \%$ of kaolin- $\mathrm{H}^{+}$and 20 hours for the reaction time.

\section{Acknowledgement}

We thank all staff of laboratory of applied organic chemistry (LCOA), University of Annaba for their kind cooperation.

\section{References}

[1] Dale, J. (1993). The Contrasting Behaviour of Oxirane and Oxetane in Cationic Cyclooligomerization and Polymerization. Tetrahedron, 49: 8707-8725.

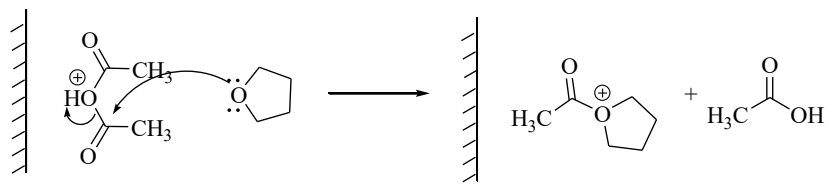

(a)

Scheme 3. Reaction between protonated acetic anhydride and THF monomer

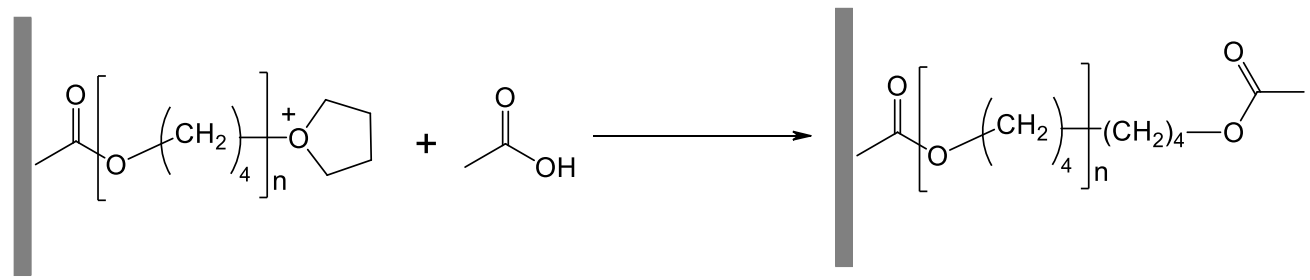

Scheme 4. Ring-opening polymerization reaction of tetrahydrofuran 
[2] Won Kang, J., Kyoo Han, Y. (1997). Polymerization of Tetrahydrofuran with New Transition Metal Catalyst and its Mechanism:(pMetylbenzyl)-O-Cyanopyridinium Hexafluoroantimonate. Bulletin of the Korean Chemical Society, 18: 433-438.

[3] Clark, J.S., Elustondo F., Trevitt, G.P., Boyall, D., Robortson, J., Blake, A.J., Wilson, C., Stammen, B. (2002). Preparation of Cyclic Ethers for Polyether Synthesis by Catalytic Ring-Closing Enyne Metathesis of Alkynylethers. Tetrahedron, 58: 1973-1982.

[4] Javakannan, M., Ramakrishnan, S. (2001). Recent Developments in Polyether Synthesis. Macromolecular Rapid Communications, 22: 1463-1473.

[5] Shibayama, M., Takahashi, H., Nomura, S., Imai, M. (1998). Isothermal Crystallization offend-Linkedpoly(Tetrahydrofuran) Networks. 3. Small-Angle Neutron Scattering. Polymer, 39: 3759-3766.

[6] Aouissi, A., AL-Deyab, S.S., AL-Shehri, H. (2010). The Cationic Ring-Opening Polymerization of Tetrahydrofuran with 12tungstophosphoric Acid. Molecules, 15: 13981407.

[7] Niyomthai, T., Jongsomjit, B., Praserthdam, P. (2018). Impact of $\mathrm{AlCl}_{3}$ and $\mathrm{FeCl}_{2}$ Addition on Catalytic Behaviors of $\mathrm{TiCl}_{4} / \mathrm{MgCl}_{2} / \mathrm{THF}$ Catalysts for Ethylene Polymerization and Ethylene/1-Hexene Copolymerization. Bulletin of Chemical Reaction Engineering \& $\mathrm{Ca}$ talysis, 13(3): 393-404.

doi: 10.9767/bcrec.13.3.2116.393-404.

[8] Kušan, J., Keul, H., Höcker, H. (2013). Block Copolymers Comprising a Polytetrahydrofuran Block and One or Two [5]-polyurethane Block(s): Synthesis and Characterization. e-Polymers, 1: 94-102.

doi: 10.1515/epoly.2001.1.1.94.

[9] Aouissi, A., AL-Deyab, S.S., AL-Shehri, H. (2010). Cationic Ring-Opening Polymerization of Tetrahydrofuran with Keggin-Type Heteropolycompounds as Solid Acid Catalysts. Chinese Journal of Polymer Science, 28: 305-310.

[10] Yahiaoui, A., Belbachir, M., Soutif, J.C., Fontaine, L. (2005). Synthesis and Structural Analyses of poly (1,2-Cyclohexene Oxide) over Solid Catalyst. Materials Letters, 59: 759-767.

[11] Kadokawa, J., Lwasaki, Y., Taqaya, H. (2002). Ring-Opening Polymerization of Lactones Catalysed by Ion-Exchanged Clay Montmorillonite. Green Chemistry, 4: 14-16.

[12] Chandramohan, A., Mandhakini, M., Dinakaran, K., Alagar, M. (2012). Preparation and Characterization of Vinyl Ester MonomerToughened Epoxy-Clay Hybrid Nanocomposites: Thermal and Morphological Properties.
International Journal of Polymer Analysis and Characterization, 17: 477-484.

[13] Aslya, A., Harrane, A., Belbachir, M. (2016). Polymerization of DL-Lactide induced by Protonated Montmorillonite Clays as a Solid Catalyst: Mechanism Study. Materials Research, 19: 132--137.

[14] Harrane, A., Meghabar, R., Belbachir, M. (2002). A Protons Exchanged Montmorillonite Clays as an Efficient Catalyst for the Reaction of Isobutylene Polymerization. International Journal of Molecular Sciences, 3: 790800.

[15] Yahiaoui, A., Belbachir, M. (2006). RingOpening Polymerization of Styrene Oxide with Maghnite $-\mathrm{H}^{+}$as Ecocatalyst. Journal of Applied Polymer Science, 100: 1681-1687.

[16] Kherroub, D., Belbachir, M., Lamouri, S. (2018). Green Polymerization of Hexadecamethylcyclooctasiloxane Using an Algerian Proton Exchanged Clay Called Maghnite-H+. Bulletin of Chemical Reaction Engineering \& Catalysis, 13: 36-46.

[17] Ayat, M., Belbachir, M., Rahmouni, A. (2016). Selective Synthesis, Characterization and Kinetics Studies of poly(a-Methyl styrene) induced by Maghnite-Na+ Clay (Algerian MMT). Bulletin of Chemical Reaction Engineering \& Catalysis, 11: 376-388.

[18] Meghabar, R., Megherbi, A., Belbachir, M. (2003). Ecocatalyst for Cationic Polymerization of N-vinyl-2-pyrrolidone. Polymer, 44: 4097-4100.

[19] Belmokhtar, A., Sahli, N., Yahiaoui, A., Belbachir, M. (2007). Polycondensation of Pyrrole and Benzaldehyde Catalyzed by $\mathrm{Ma}$ ghnite- $\mathrm{H}^{+}$. eXPRESS Polymer Letters, 1: 443449.

[20] Rahmouni, A., Belbachir, M. (2016). Green Synthesis of Cationic Polyacrylamide Composite Catalyzed by an Ecologically Catalyst Clay Called Maghnite-H+ (Algerian MMT) Under Microwave Irradiation. Bulletin of Chemical Reaction Engineering \& Catalysis, 11: 170-175.

[21] Harrane, A., Naar, N., Belbachir, M. (2007). Ring-Opening Polymerization of Oxetane by the Use of a Montmorillonite Clay as Catalyst. Materials Letters, 61: 3555-3558.

[22] Ouis, N., Benharrats, N., Belbachir, M. (2004). Synthèses de Polytétrahydrofurane Catalysées par le kaolin de tamazert. Comptes Rendus Chimie, 7: 955-962.

[23] Kherroub, D., Belbachir, M. Lamouri, S. (2017). Synthesis and Characterization of Polyvinylmethylsiloxanes by Cationic Polymerization Using a Solid Green Catalyst. e-Polymers, 17: 439-448. 
[24] Hartati, H., Widati, A., Dewi, T., Prasetyoko, D. (2017). Direct Synthesis of Highly Crystalline ZSM-5 from Indonesian Kaolin. Bulletin of Chemical Reaction Engineering \& Catalysis, 12: 251-255.

[25] Dang, T.H., Chen, B.H., Lee, D.J. (2013). Application of Kaolin-based Catalysts in Biodiesel Production via Transesterification of Vegetable Oils in Excess Methanol. Bioresource Technology, 145: 175-181.

[26] Benkenfoud, K., Harrane, A., Belbachir, M. (2012). Ring Opening Polymerization of Tetrahydrofuran Catalysed by Maghnite- $\mathrm{H}^{+}$. Chinese Journal of Polymer Science, 30: 5662.

[27] Kumar, S., Panda, A. K., Singh, R.K. (2013). Preparation and characterization of acids and alkali treated Kaolin clay. Bulletin of Chemical Reaction Engineering \& Catalysis, 8: 6169.
[28] Ferrahi, M.I., Belbachir, M. (2003). Polycondensation of Tetrahydrofuran with Phthalic Anhydride induced by a Proton Exchanged Montmorillonite Clay. International Journal of Molecular Sciences, 4: 312-325.

[29] Boulmokh, A., Berrejem, Y., Guerfi, K., Gheid A. (2007). Kaolin from Djebel Debbagh Mine, Guelma, Algeria. Research Journal of Applied Sciences, 2:435-440.

[30] Fan, W.W., Fan, X.D., Tian, W., Liao, X.Q., Zhang, W.B., Mu, C.G.; Kong, J. (2013). Poly (ethyleneglycol)-poly(tetrahydrofuran)poly(ethyleneglycol) triblock copolymer: synthesis, crystallization behavior and novel morphology. eXPRESS Polymer Letters, 7: 416-430.

[31] Reguieg, F., Sahli, N., Belbachir, M., Lutz, P.J. (2006). One-step Synthesis of bisMacromonomers of poly(1,3-dioxolane) catalyzed by Maghnite- $\mathrm{H}^{+}$. Journal of Applied Polymer Science, 99: 3147-3152. 